\title{
Construction of Buildings on Peat: Case Studies and Lessons Learned
}

\author{
Ali Abdul-Wadoud Mahmod ${ }^{1, a}$, Sabarudin Mohd ${ }^{1}$, Mohd Idrus Mohd Masirin², Saiful Azhar Ahmad \\ Tajudin $^{2}$, Ismail Bakar ${ }^{2}$, Adnan Zainorabidin ${ }^{2}$, Azrul Zulwali Kifli ${ }^{1}$ and Ling Jen Hua ${ }^{1}$ \\ ${ }^{1}$ Peat Technology Research Institute, University College of Technology Sarawak, 96000 Sibu, Sarawak, Malaysia \\ ${ }^{2}$ Research Center for Soft Soil, Universiti Tun Hussein Onn Malaysia, 86400 Parit Raja,Johor, Malaysia
}

\begin{abstract}
Building construction on soft soils including on peat has many challenges and difficulties. The failed and deteriorated buildings have a big impact on the community. The IConCEES International Workshop 2015 which was conducted on October 2015 convened as a joint venture between Universiti Tun Hussein Onn Malaysia (UTHM) and the University College of Technology Sarawak (UCTS). The aim was to invite regional experts from academia and the industry to formally present and discuss the various construction problems encountered when working with peat. The discussions were divided into two divisions; infrastructure and building construction. This paper discusses the outcomes of the workshop and focuses on the factors and relevant challenges when constructing buildings on peat. The experts have discussed regulatory and construction issues including: drainage issues, site investigation practices, monitoring and construction guidelines. A few suggestions were outlined as a remedy to these problems and to better assist the peat practitioner at work.
\end{abstract}

\section{Introduction}

Peat is that separated soil material consisting mainly of plant remains in various degrees of decomposition; fibric, sapric and hemic. Peat in characterized by its very high moisture content, high compressibility and very low shear strength. Consequently, building on peat entails a huge amount of uncertainty, as all textbook bearing capacity, consolidation and shear strength theories are based on inorganic soils. Hence it is vital that special work and more research be conducted on peat to overcome this difficulty and to further understand its behavior.

Peatland is widely scattered all over Southeast Asia and Malaysia. Figure 1 shows the distribution of Peatland in Southeast Asia, of which Malaysia is an integral part. Knowing this it becomes vital for construction engineers to study the impact of construction on peat in its various forms of decomposition.

As such, a workshop co-organized by Universiti Tun Hussein Onn Malaysia (UTHM) and The University College of Technology Sarawak (UCTS) was held on the grounds of UCTS to discuss the various construction issues on Peat. Experts and panelists from all over the Peat engineering industry spectrum discussed in two days all the relevant construction issues and problems attributed to working on Peat subsoil. The workshop was divided into two separate sessions: infrastructure and

\footnotetext{
${ }^{\text {a }}$ Corresponding author : ali.mahmood@ucts.edu.my
} 
superstructure/buildings. While this paper is devoted to the discussion on the superstructure/building presentations and session, another will present the results and discussion on the infrastructure session. The superstructure/building session was further subdivided into two parts, the presentations and the plenary session.

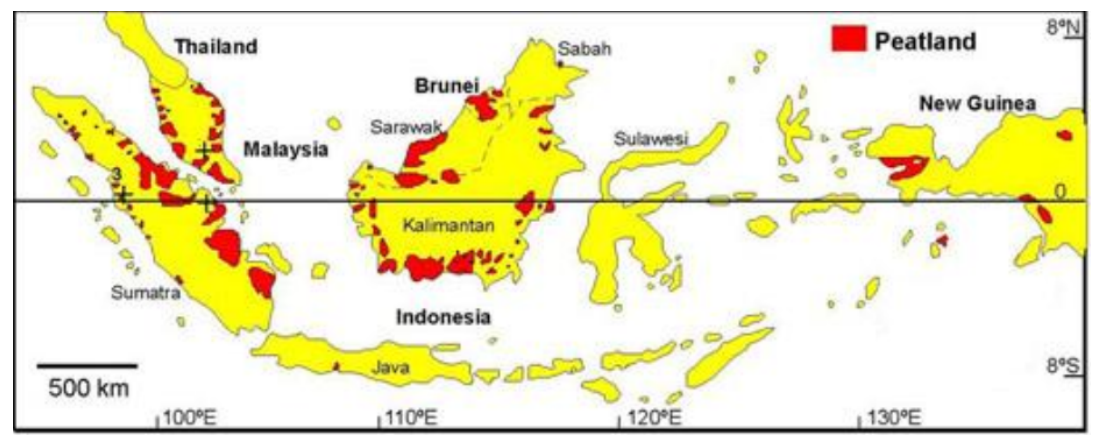

Figure 1. The distribution of peatland in Southeast Asia [4].

\section{Sharing of Experiences and Knowledge}

\subsection{Challenges and reducing building failures}

Mohd Masirin [1] discussed an overview on the construction of buildings and the effect due to the presence of Peat on the structural integrity and livelihood of buildings. Continuous monitoring for buildings on Peat is required and appropriate design considerations and materials are essential in order to minimize construction defects. Implications of tipping, differential and uniform settlement on buildings were described, as well, with Sibu, Sarawak, as a case study. It is common knowledge that foundation makes the cost of constructing a building on Peat relatively high due to the nature of the underground formation. Preconstruction difficulties, post construction failures, cost for construction, maintenance issues, short and long term impacts for construction on peat were discussed. Seven recommendations were outlined in order to avoid construction problems on peat, they are, among others, introduction of appropriate and suitable soil improvement methods, identification of suitable building designs, introduction of a technique to safeguard the foundation against dewatering effects, using lightweight materials for buildings and strengthening the foundation with appropriate methods for long term resilience against consolidation. Construction technologies on peat, currently employed by engineers, among others, are: piled foundation, raft foundation, light weight concrete, stabilized soil on Peat and geogrids. Continuous research on construction methods and materials is demanded, to determine an economic and effective solution. However, standards and guidelines need to be established in order that JKR and other local agencies are able to better evaluate developers' project proposals before any endorsement are made.

\subsection{Case studies of building construction failures on peat}

Phienwej [2] described the various structural and physical problems associated with construction on Peat and suggested some remedies. There are four case studies highlighted; (i) the subsidence in Ramkhanhaeng University area, Bangkok, (ii) the campus of the Asian Institute of Technology, (iii) the Nakhon Luang Aquifer, and (iv) Bangkok International Airport. Prefabricated vertical drains (PVD) were implemented as a remedy to the airport subsidence problem. It was, also, suggested that several techniques could be applied to other cases to strengthen the soil such as: vacuum consolidation and lightweight materials and soil cement columns for deep mixing methods. Figure 2 shows some foundation subsidence in the Asian Institute of Technology [2]. 


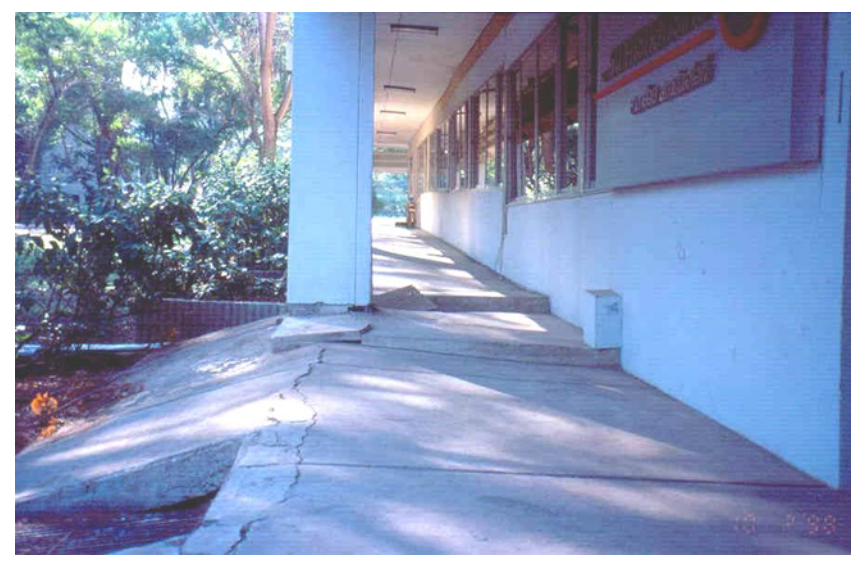

Figure 2. Some foundation subsidence in the Asian Institute of Technology in Thailand [2].

\subsection{Case study on bridge failure}

Ong [3] described the construction of a $13.5 \mathrm{~km}$ single-carriageway linking the existing Igan Bridge to a proposed university site in Sibu, Sarawak, East Malaysia. The soft soils of maximum $30 \mathrm{~m}$ thick, which were found below the 5-m thick Peat layer. They were treated with pre-fabricated vertical drains to reduce post-construction settlements so that design requirements were met. After site investigation and soil characterization tests, it was successfully constructed using hydraulically placed sand-fill to replace the underlying fibrous peat. Settlement plates were installed to monitor the settlement of the sand layer-PVD system. It was shown that the rate of settlement increased markedly when PVD was installed. Field instrumentation results cross-checked with Asoaka observational method to measure settlements was successfully implemented to provide a good understanding of ground treatment of fibrous peat and soft soil. Figure 3 shows the installed PVD and the settlement plates [3].
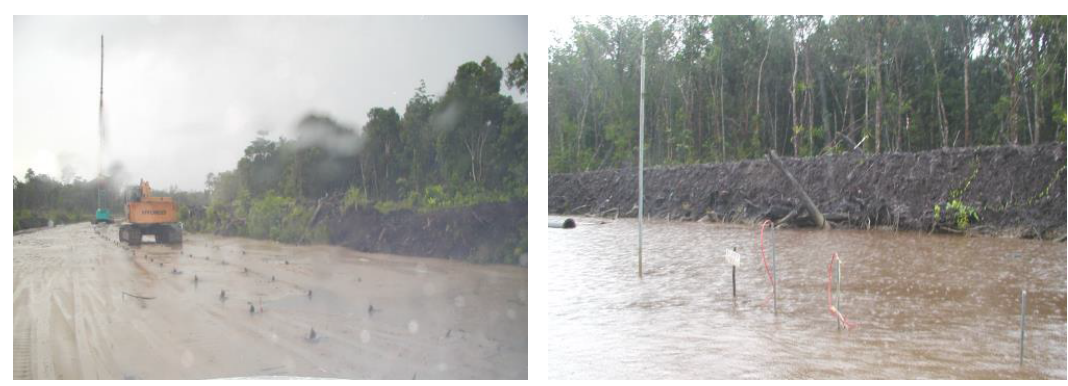

Figure 3. a) (left) PVD installed after sand-fill reached existing ground level and b) (right) condition of settlement plates when site was flooded [3].

\subsection{Physio-chemical behaviour of peat}

Nazir [4] emphasized that the construction and design guide for the various types of Peats, which are: Hemic, Sapric and Fibric, should be outlined for engineers. Full scale site studies need to be conducted to determine the most suitable Peat stabilization and reinforcement methods. Proper site investigation needs to be thoroughly conducted to determine the various heterogeneous types of Peats present. The physio-chemical behavior of tropical peat and the most effective economical methods need to be understood and further investigated. 


\subsection{Case study on housing project construction}

Jafaar [5] investigated a structural building failure on soft soil. A case study of a housing units in Shah Alam, Selangor was discussed. It was revealed that irregular settlement of foundation structure has occurred due to foundation settlement, which was caused by lack of consultant supervision during construction. It was also revealed that no problem on the design and structural plans existed, which could have contributed to the failure. So it was suggested that settlement should be monitored for the affected building. In the future, proper consultant supervision should be performed on all construction projects.

\section{The Plenary Session}

\subsection{Drainage problems}

These were discussed with two case studies: the Medan mall and bus station in Sibu, Sarawak. Time and cost are the critical issues discussed and the suggested solution was to have a working platform; not temporary solution (like bamboo and geotextile mattress, which is only considered for temporary access). It was emphasized that ground treatment should not be overlooked; surrounding areas should be treated, as well. Ground water management was, also, one of the issues discussed since its drainage affects the peat foundation to a great extent. Replacement of the Peat layer to a certain depth (by sand for example) was considered as the best method. It was mentioned that building failures in Sibu were, partly, because of the type of pile (Bakau pile) used and the change in water table under drainage. Hence, it was emphasized that design of foundations has to account for lateral movement within the Peat layer. Also, as far as long term monitoring is concerned, installation of piezometers and settlement plates is mandatory.

\subsection{Site investigation practices}

These were also discussed, and it was stated that site investigation is very important before any construction work could take place. Building construction guidelines on Peat, especially for pile use in foundation engineering, need to be included in the existing Malaysian construction codes and practices. High strength concrete is required for structural use, however, lightweight concrete (replacement for brick wall or non-load bearing walls, for example) is recommended for nonstructural members.

\subsection{Monitoring}

Workshop panelists stated, that settlement is the main problem with peat soils, hence, expert opinion is required for validation on peat research in this regard. While, guidelines do not state the preferred method; the expert has to decide on it based on field and laboratory data. Current guidelines only state the two available options: replacement or reinforcement (stabilization). And, in essence, financial issues are the key. Suitable design for buildings on peat was also discussed as it relates to settlement, environmental problems and structural failures.

\subsection{Guidelines}

Guidelines for specifications on building construction on peat testing is needed, as far as preconstruction and post construction practices. While some were specified in the Guidelines presented by CREAM (Construction Research Institute of Malaysia), additional testing schemes suitable for building construction and monitoring are needed. In that regard, it is recommended that developers, consultants and contractors, as a mandatory practice, should install piezometers and settlement plates 
for short and long term monitoring of buildings constructed on Peat. Table 1 illustrates the building issues encountered and the proposed solutions discussed by the panelists.

Table 1. Building issues encountered and the proposed solutions.

\begin{tabular}{|l|l|l|}
\hline Issues encountered on site & Proposed solutions \\
\hline Drainage problems & - & Ground treatment \\
& - & Ground water management \\
& - & Peat replacement \\
& - & Design of foundations \\
& - & Long term monitoring \\
\hline Site investigation practices & - & Pile use as part of building construction guidelines \\
& - & High strength concrete for structural members \\
& - & Lightweight concrete for nonstructural members \\
\hline Monitoring & - & Suitable design for building on Peat \\
& - & Expert opinion for research validation \\
\hline Construction guidelines & - & Guidelines for specifications on building construction on peat \\
& - & Testing needed: pre-construction and post construction \\
& - & Piezometers and settlement plates are mandatory for installation \\
& & in building on peat \\
\hline
\end{tabular}

\section{Conclusions}

Experts from academia and the industry presented and debated for two days in the IConCEES International Workshop 2015 in UCTS the impact of building construction on peat. Various construction problems and issues were thoroughly discussed including drainage issues, site investigation practices, monitoring and construction guidelines. The panelists suggested solutions to overcome these construction problems. However, more work needs to be done in terms of both regulation and research before building construction on peat can be fully implemented with the minimum amount of settlement and drainage problems.

\section{Acknowledgment}

The authors would like to acknowledge with gratitude the priceless support and expert opinion rendered by the keynote and expert speakers during IConCEES International Workshop 2015. This includes YB Datuk Dr. Abu Bakar Mohamad Diah, Prof. Ir. Dr. Zuhairi Abdul Hamid, Assoc. Prof. Dr. Noppadol Phien-wej, Assoc. Prof. Ir. Dr. Naser Abdul Ghani, Prof. Ir. Dr. Ramli Nazir, Prof. Dr. Fauziah Ahmad, Ir. Liew Shaw Shong, Dr. Ir. Slamet Widodo, Dr. Ir. Dominic Ong Ek Leong, Ir. Ghazali bin Abd Aziz, Assoc. Prof. Ir. Dr. Abd Halim and Ir. Muhd Salmizi Ja'afar.

\section{References}

[1] M.I. Mohd Masirin, Peat and building construction, IConCEES International Workshop 2015, Sibu, Sarawak, (2015).

[2] N. Phienwej, Thailand experiences in geotechnical difficulties in road and embankment construction in soft soils, IConCEES International Workshop 2015, Sibu, Sarawak, (2015).

[3] D.E.L Ong, Alternative method of road embankment construction on fibrous peat using hydraulic sand-fill, IConCEES International Workshop 2015, Sibu, Sarawak, (2015).

[4] R. Nazir, A review on Malaysia peat soil properties for construction purposes, IConCEES International Workshop 2015, Sibu, Sarawak, (2015).

[5] M.S. Jafaar, Construction on peat: Case study on soft soil building construction, IConCEES International Workshop 2015, Sibu, Sarawak, (2015). 